\title{
LEGAL AND INSTITUTIONAL METHODS APPLIED TO ORDERS TO STOP PAYMENT OF CHECKS- II. INSTITUTIONAL METHOD
}

\section{UNDERHILL MOORE, GILBERT SUSSMAN AND C. E. BRAND $†$}

IN a companion article, ${ }^{1}$ Steiner $v$. Germantown Trust Company ${ }^{2}$ was approached by way of a dialectic of legal propositions. In the present article it is proposed to make an institutional study of the case. $^{3}$ In 1931 such a study ${ }^{4}$ was made of Callaham $v$. Banls of Anderson, ${ }^{5}$ Delano v. Equitable Trust Company, ${ }^{6}$ and Goldstein v. Jefferson Title and Trust Company. ${ }^{7}$ The making of an institutional study of the Steiner case will make it possible to observe whether it discloses the same association between the behavior of the litigants, the institutional patterns of the jurisdiction and the decision, that the study of those three cases tended to disclose.

It may be worthwhile to restate the hypothesis which underlies the proposed study. That hypothesis is that the patterns to which the overt behavior in a locality more frequently conforms are among the cultural factors in a litigation-situation significantly connected with the decision, that the significance for prediction attributed in legal literature to past decisions is erroneously attributed, and that the semblance of likeness between decisions, when it does appear, does not indicate any predictive value in past decisions but rather a significant association of the decisions with another variable, i.e., the institutional patterns in the locality of the court. It is probable

$\leftarrow$ Underhill Moore is a Sterling Professor of Law, Yale University; Gilbert Sussman is a Research Assistant, School of Law, Yale University; C. E. Brand is a third year student, School of Law, Yale University.

The authors acknowledge their indebtedness to Emma Corstvet of the Institute of Human Relations of Yale University for her skillful and indispensable work in the banks of Pennsylvania.

This study was supported in part by a grant from the Institute of Human Relations of Yale University.

1. Legal and Institutional Methods Applied to Orders to Stop Payment of Checks-I. Legal Method (1933) 42 YALE L. J. 817.

2. $104 \mathrm{~Pa}$. Super. Ct. 38 (1931).

3. See Moore and Hope, An Institutional Approach to the Law of Commercial Banking (1929) 38 YALE L. J. 703.

4. Moore and Sussman, Legal and Institutional Methods Applied to tho Debiting of Direct Discounts (1931) 40 Y ALE L. J. 381, 555, 752, 928, 1055, 1210.

5. 69 S. C. 374,48 S. E. 293 (1904).

6. 110 Misc. 704, 181 N. Y. Supp. 852 (Sup. Ct. 1920).

7. $95 \mathrm{~Pa}$. Super. Ct. 167 (1928). 
that the notion of a court as to the just, reasonable, fair and convenient way for customer and bank to behave and also as to the just, reasonable, fair and convenient consequence which should be attached to the way the parties did behave is so associated with the more frequent and, therefore, regular overt behavior in such situations in the locality as to serve as an index useful in prediction. Though overt behavior which is frequent and regular may not have directly impinged, frequently or at all, upon the court, yet verbal symbols which do reflect that overt behavior, even though obscurely, or other behavior closely connected with it, have impinged upon the court. ${ }^{8}$

A method for the systematic study of the association between a decision, the behavior of the litigants ("the facts") followed by that decision and current institutional overt behavior patterns has been formulated ${ }^{9}$ and was applied to the Callaham, Delano and Goldstein cases. In order to make the results of the institutional study of the Steiner case comparable with the results of the study of those cases the same method must be applied to the Steiner case. That method provides, firstly, a procedure for analysis of behavior (institutional and non-institutional) into transactions. Secondly, it provides for the determination of what transactions are sequential (institutional). Thirdly, it provides a procedure for the choice of the sequence with which each of the transactions is to be compared in finding the type and degree of its deviation, if any. Fourthly, it provides a crude instrument for measuring the degree of deviation by means of a rating based on the judgment of informed persons.

I

The Steiner case was decided in the first instance in the Municipal Court of the County of Philadelphia, ${ }^{10}$ and on appeal in the Superior Court of Pennsylvania. The judges of the Municipal Court are elected from the county at large and must be residents of the County of Philadelphia; the judges of the Superior Court are elected from the State at large, and must be residents of Pennsylvania.11 Consequently the application of the method requires the finding of the

8. Moore and Sussman, The Lawycr's Law (1932) 41 YALE L. J. 566, 570-574.

9. Moore and Hope, supra note 3.

10. The territory of the city and county of Philadelphia are co-extensive.

11. Pa. Const., art. 5, § 19; PA. Stat. ANN (Purdon, 1930) tit. 17, §§ 111, 681 ; tit. $65, \S 91$. 
institutional patterns or sequences in Pennsylvania. Since a comparison of the behavior of the litigants with patterns of institutional behavior is the objective, the investigation may be limited to a search for those sequences, if any, with which the behavior of the litigants should be compared.

The comparison which the method requires is a comparison in detail of the successive segments of the behavior of the parties with corresponding segments of institutional behavior. The segments which have been chosen as units are transactions. ${ }^{12}$ In order, therefore, to plan the investigation it is necessary: first, to arrange the behavior of the litigants in transactions; secondly, to conceivo all the possible transactions which might be sequences ${ }^{13}$ with which

12. "The subject-matter of any field of investigation may be considered as a class of entities possessing the common factors by which the field is defined. The subject-matter of a field of investigation whose subject-matter is behavior may be considered as a class of segments of behavior possessing the common factors by which the field is defined. A segment of behavior is a succession of events of behavior. A segment of behavior which is an entity is a succession of events of behavior in some relation with each other. The rolation chosen to determine the events constituting such a segment of human behavior might have been, but was not, solely a space-time relation (e.g., all events occurring today in this room).. The relation chosen was rather that often crudely referred to as the relation of cause and effect, or the causal relation." Tho greatest segment of human behavior in causal relation and possessing tho common factors by which the field is defined will be referred to as a transaction-series. The least segment of behavior in causal relation and possessing the common factors by which the field is defined will be referred to as a transaction. A transaction-series is obviously a succession of one or more transactions in causal relations with each other."

* "A particular event $\mathrm{E}$ may be said to be in causal relation with another particular event $e$ if the likelihood that event $\mathrm{E}$ will be succeeded by events $e, e_{1}, e_{2}, e_{3}$, etc., at particular intervals of space and time is greater than tho likelihood that it will be succeeded by other particular events.

"The likelihood referred to is not an a priori mathematical probability. That cannot be computed since the equally likely cases cannot be enumerated. It is not an a posteriori statistical probability. That has not been obsorved. It cannot too strongly be intimated that the judgment as to likelihood which is here supposed is a qualitative subjective judgment, and not a qunntitativo objective judgment. The word likelihood is used in this same sunso hereafter. It refers neither to the result of a mathematical inference nor to the result of a statistical observation." Moore and Hope, supra note 3, at 706.

13. "Classes of transactions may also be organized with reference to descriptive similarity (looking alike, rather than having like consequences). Such classes are defined by a generalized description of the transactions of which the class is composed. An hypothetical transaction corresponding point for point with such a generalized description is, if the class of transactions which is defined by that description is sufficiently large, referred to as $n$ sequence. An actual transaction which would, if hypothetical, be a sequence, is referred to as a sequential transaction. An actual transaction-sories con- 
the behavior of the litigants should be compared; and thirdly, to limit the investigation to a search for those possible transactions which, on the basis of a preliminary judgment, seem likely to be found to be sequences. ${ }^{14}$

When the behavior of the litigants in the Steiner case is arranged in transactions, it discloses a transaction-series of three transactions. The behavior of the litigants ("the facts") which is referred to is that described in the record ${ }^{15}$ and not that described in the published report. ${ }^{16}$ The record and briefs rather than the report should be resorted to because the behavior of the parties which impinged upon the courts, and not merely so much of their behavior as the courts thereafter happened to mention in their opinions, must be considered in an institutional analysis. ${ }^{17}$

The behavior of the litigants described in the record is arranged in a transaction-series as follows:

\section{Balänce $\$ 213$}

There were transactions on the checking account of the plaintiff, a customer, with the defendant, a bank doing a commercial banking business in Philadelphia and maintaining several banking offices, which transactions had the consequence, on July 30, 1929, of a credit balance of $\$ 213$.

stituted of sequential transactions is referred to as a scqucntial transactionseries.

"Institutional behavior (i.e., behavior which frequently, repeatedly, usually occurs) may thus be defined as a class of sequential transactions. Actually, transactions are preceded, accompanied, and followed by other transactions. Some sequential transactions may frequently succeed certain series of sequential transactions. The relation of frequently following-frequently preceding is referred to as the institutional relation. The class of transactions which satisfies the condition of being sequential transactions in institutional relation is referred to as the institution. Sequences in institutional relation are referred to as institutional sequences.

"The institutional analogue to a transaction-series is referred to as a sequence-series.

"Any actual transaction which does not satisfy the condition of being a sequential transaction in institutional relation is referred to as a deviational transaction." Id. at 707 .

14. See IToore and Sussman, supra note 4, at 555, 571.

15. The printed record on appeal to the Superior Court (Philadelphia District, October Term 1931, No. 246) contains a transcript of the stenographer's minutes.

16. The report of the Steiner case contains a somewhat misleading statement of facts.

17. See Moore and Sussman, supra note 4 , at $555,567$. 


\section{First Transaction}

1. Thereafter on July 30 , the customer drew two checks on the bank, dated July 30 and numbered, one for $\$ 200$ and the other for $\$ 13$, to the order of a named payee, and handed them to a third person for the payee.

2. Thereafter on the same day, the checks were presented for certification over the counter at the main office to a paying teller.

3. The paying teller to whom the checks were presented certified them (a few seconds before he was notified of the order to stop payment referred to in the second transaction).

\section{Second Transaction}

1. In the meantime on the same day, the customer telephoned the manager of the bank's Logan branch office, at which the customer regularly transacted his business, an order to stop payment of the checks. ${ }^{18}$ In the communication the checks were identified

18. Q. On the 30th of July, 1929, you drew two checks, one for $\$ 200$ and one for $\$ 13$ ? A. I did. Q. Where were they drawn? A. In the Widener Building. Q. Where is that located? A. Juniper and Penn Square. Q. Philadelphin? A. Philadelphia. Q. What time of the day was it? A. 1:15, July 30th. Q. Was that in the afternoon? A. P.M., yes. Q. Then what happened aftor 1:15 on July 30,1929 ? A. The man I gave the checks to was to report back in 15 minutes; when he didn't report back I immediately called up the branch of the bank where I do business. ... .

Q. You gave him the checks in the Widener Building? A. Got in there about ten after one. Q. Was this his office? A. His office. Q. Why was ho supposed to report back to you in 15 minutes? A. Well, when he didn't roport back in 15 minutes I became suspicious. Q. I asked you why ho was supposed to report back in 15 minutes? A. He was to come back with some writton orders for merchandise to the amount of these two checks; when ho didn't come back in 15 minutes I became suspicious and I immediately called up the bank. Q. From whom were the orders to come? A. I don't know who the goods were to come from. He was supposed to be the agent for the concern the goods were coming from and I had no knowledge who the firm woro. Q. Were you doing business with this company? A. Never before. Q. On this occasion? A. Yes. Q. Had you given him any order for anything? A. It was to have been a cash transaction. Q. You were ordering material from him, ordering goods from him? A. Yes. Q. Had you given him an ordor? A. Yes. Q. You had given him an order? A. Yes. Q. What was ho supposed to do with those orders? A. He was supposed to bring in typowritten letters to the concern that these goods were to come from to the amount of theso two checks. Q. Where did he have to go to get these typowritten lettors? A. In the building he was supposed to go, I think on the same floor that the attorney has his office. Q. Where? A. I think on the 8th floor of the Widenor Building-I think there is a public stenographer there. Q. What was the nature of the goods that you ordered? A. The $\$ 13$ order was chewing gum and the other was a vending machine. Q. How many of them? A. Thero 
by reference to the number, date, payee and amount or by reference to some of them. The customer did not state a reason for stopping payment. The next morning he, in person, orally contirmed the order.

2. Thereafter the branch manager communicated, by telephone, the order to stop payment to a paying teller at the main office.

3. Thereafter the paying teller at the main office who received the order to stop payment notified, by word of mouth, the three paying tellers then present in the banking room.

The last paying teller to be notified, who had certified the checks a few seconds before, was notified according to the witnesses for the bank, five minutes after the time at which occurred the telephone conversation referred to in the first paragraph of this transaction; twenty minutes after the time of the telephone conversation according to the plaintiff's own testimony.

\section{Third Transaction}

1. Thereafter the customer demanded of the bank the sum of $\$ 213$ as the balance of his checking account.

2. The bank refused to honor the demand of the customer.

It will be observed that all three of the foregoing transactions have the likelihood of consequences which bring them within the deposit currency field, and are within the extinguishment subdivision of that field. This is obviously true of the first and third transactions. The second transaction is also in that subdivision by virtue of possessing the likelihood, which either is or is not actualized, of frustrating another transaction's likelihood of extinguishment.19

were eight machines at $\$ 25$ apiece. Q. And he had to go to this other office? A. He had to go to the 8th floor to have these letters written by the public stenographer and he said it wouldn't take over 15 minutes, he would be backs precisely. Q. Were those letters to be signed by him? A. To be signed by him. He received the checks for the goods. Q. What was his name? A. George Brice. Q. And you expected him to do that all in 15 minutes? A. Yes, sir, that is reasonable time to go from the 5th floor to the 8th and back. He had an appointment with this lady and she was waiting for him. Q. How do you know that? A. By his word. Q. When he didn't come back in 15 minutes you called up the bank and talked to Mrr. Bedford? A. I did.

19. "Deposit currency is but one among many forms of commercial bantcredit; it is credit on the current checking account. Deposit currency of a particular bank in favor of a particular customer exists in the amount of the balance of the current checking account of that customer with that banl: The term balance is here used in a special sense, to refer to the amount of dcposit currency of a particular customer. The balance may be described as the limiting 
One of the comparable sequences for the first transaction is known. No investigation is necessary to establish that, in Pennsylvania, the drawing, delivery, presentment and honoring of a check for all or part.of the customer's balance is sequential. Whether there are comparable sequences in which the check is not honored must be determined by investigation. Investigation must also be directed at finding the sequences, if any, for the stopping of payment of checks. The finding of the sequences comparable to the third transaction does not require investigation. It is clear that the honoring by a bank of a demand made by the customer over the counter for all or part of his balance is sequential and that it is also sequential for a customer to limit his demand to an amount not greater than his balance.

In July, 1932, interviews were secured with the officers of about 15 banks in Philadelphia which maintained more than one office and information obtained from them as to stop payment practice. On the basis of this preliminary investigation, the types to which stop payment transactions in Pennsylvania were likely to conform, that is to say, the likely possible stop payment sequences, were formulated, and, in part, enumerated. Some of the aspects of behavior taken into account in the formulation of the likely possible types were (1) the operation by the bank of one or more than one office,

amount up to which checks are likely to be drawn by the customer and honored by the bank. This description is obviously incomplete; nevertheless, it suffciently approximates a description which to be exhaustive would of necessity enumerate many other sorts of behavior.

"Deposit currency of a particular customer is created when the balance of that customer increases. Deposit currency of a particular customer is extinguished when the balance of that customer decreases. Deposit currency of a particular customer is transferred when the balance of that customor decreases and the balance of another customer (the transforee) of the samo or another bank increases. Accounts between, for example, buyers and sellors are liquidated when it becomes unlikely that thereafter paymont will bo eithor demanded or offered.

"The field of investigation is constituted of transactions which have oither resulted in the creation of deposit currency, the extinguishment of deposit currency, the transfer of deposit currency, the liquidation of accounts by menno of transfer of deposit currency, or which have created a likelihood that ono or another such result would follow but, without any such result, havo tormlnated by its becoming no longer likely.

"The field of investigation is divided into four main subdivisions. A transaction may fall within more than one subdivision. As between some subdivisions this is obviously true; it could readily be shown to be true as among any subdivisions. If a particular transaction falls in more than one subdivision, in each of those subdivisions particular attention is paid only to that aspect of the transaction which brings it within that subdivision." Mooro and Hope, supra note 3, at 710 . 
(2) the office to which the order to stop payment is communicated by the customer, i.e., the main office, or a branch office, (3) the time interval between the first receipt of the order to stop payment at the main office, either from the customer or by relay from a branch office, and the completion of the process of notifying all tellers at the main office or all tellers at the main office and at least one person at each branch office. ${ }^{20}$ From a consideration of these likely possible types it appeared that the study should be confined, at least initially, to banks which, like the Germantown Trust Company, operated more than one banking office.21 The stop payment transactions in these banks, if they constituted a large or numerous enough group, would be those from which it must be determined which, if any, of the likely possible types were sequences in Pennsylvania. Of course, if the investigation revealed that the stop payment transactions in these banks were not sufficiently numerous so that their frequency could be taken to indicate the existence of institutional patterns in Pennsylvania, then it would be necessary -to determine the stop payment sequences in Pennsylvania from a study of the stop payment transactions in all banks in Pennsylvania, those operating only one office as well as those operating more than one.

Accordingly worksheets with the following headings were prepared:

Bank No. Stop Payment Orders Received on August , 1932.

1a. Did customer give first notice to main office? If so, indicate the time when received.

b. Did customer give first notice to branch office? If so, indicate the time when received.

2. If notice given to branch office, indicate the time when notice was relayed to main office.

3. Indicate the time when relaying notice of stop payment to tellers, branch tellers and bookkeepers was completed.

4a. If notice was originally given to main office, by whom was it received (officer, teller, etc.) ?

$b$. If notice was originally given to branch office, by whom was it received

(1) at branch office?

(2) at main office when relayed to main office?

5. Indicate the form of the first notice from the customer:

Telephone

Letter

Printed form

20. Moore and Sussman, supra note 4 , at 555, 571-574.

21. See pages 1209-1210, infra. 
Telegram

Telegram with recognition code

Oral

6. Does letter or form bear signature appearing on signature card?

7. If first notice by telephone or telegram, was there a confirmation

(a) by letter? If so, indicate the date and time when received.

(b) by printed form? If so, indicate the date and time when received.

(c) in another way? If so, indicate the date and time when received.

8. Does confirmation bear signature appearing on signature card?

9. Give description indicated in stop payment notice as to:

(If description in confirmation differed Number from that in first notice, indicate difference below.)

Date

Payee

Amount

Other

10. Indicate reason given for stopping payment.

11a. Does customer make his deposits at main office?

b. Does customer make his deposits at branch office?

Bank No. Stop Payment ORders Revored oN August , 1932.23

1a. Did customer give revocation of stop notice to main office? If so, indicate the time when received.

b. Did customer give revocation of stop notice to branch office? If so, indicate the time when received.

.2. If revocation given to branch office, indicate the time when it was relayed to main office.

3. Indicate the time when relaying notice of revocation to tellers, branch tellers, and bookkeepers was completed.

4a. If revocation was originally given to main office, by whom was it received (officer, teller, etc.)?

$b$. If revocation was originally given to branch office, by whom was it received

(1) at branch office?

(2) at main office when relayed to main office?

5. Indicate the form of the revocation from the customer:

Telephone

Letter

Printed form

Telegram

Telegram with recognition code

Oral

6 Does letter or form bear signature appearing on signature card?

7. If revocation by telephone or telegram, was there a confirmation

22. The information derived from the answers to the questions on this worksheet was not used in this study and therefore is not reported. 
(a) by letter? If so, indicate the date and time when received.

(b) on printed form? If so, indicate the date and time when received.

(c) in an other way? If so, indicate the date and time when received.

8. Does confirming letter or form bear signature appearing on signature card?

9. What was the date of the stop payment notice?

10. Give description indicated in revocation as to: Number

Date

Payee

Amount

11. Indicate reason given for revocation.

Other

Bank No. Checks (ON Which Stop Payarent Orders

Received) Presented on August , 1932.

1. When was check presented? Indicate date and time.

2. Was check presented: Over the counter?

Through the clearing house?

Through the mail?

By a branch office?

3. Was description of check in stop notice correct as to:

Number?

Date?

Payee?

Amount?

Other?

4. What was done with the check? Was it: Paid?

Certified?

Returned?

5. Did the bank communicate with the drawer before paying, certifying or returning the check?

6. In case of inadvertent payment, certification and payment, etc., note below action taken by bank in way of adjustment with drawer, payee or both.

The Steiner case was decided by the trial court on April 17, 1931, and by the appellate court on January 28, 1932. It is clear that a study from bank records of stop payment transactions occurring at about the time of the decision would be desirable. The preliminary investigation, however, disclosed that the records of the banks would not supply all the information desired. Consequently, it was necessary to secure a contemporaneous record of stop payment transactions occurring at the time, August and September 1932, that the study was made. 
In August 1932, there were 42 banks in Pennsylvania doing a commercial business which operated more than one office. ${ }^{22_{a}} 18$ were in Philadelphia and 24 were scattered throughout the state. Thirtyseven banks cooperated in the making of the study. Of these, 16 were in Philadelphia and 21 were in Alleghany, Berks, Blair, Cambria, Chester, Delaware, Lycoming, Montgomery, Northampton and Schuylkill counties. Three banks, two in Philadelphia and one other, either refused or were unable to cooperate. Two banks were not visited. Of the three banks outside of Philadelphia in which a study was not made, one was in Cambria county, another in Erie county and the third in Elk county.

Before the period chosen for the recording of current stop payment transactions, arrangements for the study in ench of the 37 banks were made with an officer having authority to act for the bank. In the case of each bank, it was agreed that the worksheets would be filled in by the person, or an assistant of the person, to whom orders to stop payment are directly referred and by whom the records for the bank are made. His good will and cooperation were, in each case, secured and, where it was permitted, he was compensated for his work. A few days prior to the period of the study, a sufficient number of copies of the worksheets were delivered to him and uniform instructions given.

During the period of the study in Philadelphia the worksheets which were being filled in at each of the banks were examined by two of the authors at least once to see whether records were being secured which were contemporaneous, complete, consistent and in compliance with instructions. In Philadelphia, at the end of the period, the worksheets were collected and again examined, both before and after they were taken from the bank. The worksheets of the banks outside of Philadelphia which reported stop payment transactions during the period of the study were returned by mail and upon their receipt were scrutinized for completeness and consistency. The banks outside of Philadelphia in which no stop payment transactions occurred during the period of the study reported that fact by mail. After the receipt of the worksheets in New Haven they were reexamined and in case of doubt as to the completeness, consistency or meaning of the answers relating to any transaction, the bank was revisited or explanations were secured by correspond-

22a. The list of Pennsylvania banks in existence and having more than one branch on August 1, 1932, was obtained by an examination of the RAND MCNALIY BANKers' DiRECTORY (July, 1931) and POLK's BANK ENOYCLOPEDIA (July, 1931) and by correspondence with the Federal Reserve ngents of the Philadelphia and Cleveland Federal Reserve Banks and with the Secrotary of Banking for Pennsylvania. 
ence completing, correcting or interpreting the records. In accordance with arrangements made at the time of the five day study, each bank was visited two months after the period of the study. At that time, from records kept at the bank, the questions on the worksheets which related to the revocation of orders to stop payment and to the presentment of checks were answered. These worksheets were also examined and reexamined for completeness, consistency and meaning and corrected after further visit or correspondence.

From July 1932 to May 1938, contacts by correspondence and visit were maintained with the cooperating banks. At least two interviews were had at each of the banks which reported ston payment transactions. In addition, in the case of each of the banks which reported stop payment transactions used in the study, informed persons were interviewed once more and in the case of each of the Philadelphia banks at least trice. One of the intaxviews at each of these banks was based upon schedules devised to disclose in detail the relevant internal organization and operation of the banks and their routine for handling orders to stop payment. The visits to the banks were made by three persons who together spent about six weeks in Pennsylvania.

On the worksheets were recorded the transactions at each bank of five consecutive days, Monday to Friday, inclusive. In Philadelphia the days were August 15 to 19, inclusive; in the rest of the state, September 26 to 30, inclusive. In order to learn whether or not there were any differences, because of the change in season, between the transactions of August 15 to 19 and those of September 26 to 30 and to test the reliability of the answers on the worksheets, the transactions of a second five day period, October 4 to 8 , inclusive, were recorded in 7 of the Philadelphia banks.

Of the 37 banks, 8, all outside of Philadelphia, reported that no stop payment transactions occurred during the period of the study. Consequently, there were only 29 worksheets upon which stop payment transactions were recorded.

In respect of 7 of the 29 banks whose worksheets recorded stop payment transactions, it appeared that (1) the ledgers in which were recorded the individual accounts of customers were liept at the office at which the customer regularly transacted his business and at no other office, (2) signature cards for the customers of each office were kept at that office, (3) checks were addressed to the bankat the office at which the customer regularly transacted his business and were not drawn on the bank generally, (4) checks presented through the clearing house or by mail, though originally received at the "main office," were transmitted to the office to which they were addressed for examination of balance, signature, ct cetcra. and 
(5) orders to stop payment were received only, at the office to which the check was addressed and were not transmitted by it to any other office. Thus, each office of the 7 banks was operated in most respects as if it were an independent bank and, as a result, the stop payment transactions in each office of these banks were like those occurring in banks having but a single office. Consequently, transactions recorded upon the worksheets left at these banks do not belong within the group chosen for study in the first instance. ${ }^{23}$ In 2 of the 8 banks which reported no stop payment transactions, the relevant internal organization and operation of the bank was like that of these 7. Transactions at these banks, had they occurred, would likewise have been excluded.

Thus, there remained 22 worksheets, one for each of the 22 banks whose offices were not operated as if they were independent banks. One of the worksheets was, in effect, incomplete because certain of the questions were misunderstood. The transactions which it records are therefore not included in Tables II, III and IV. Nor are the transactions of another bank tabulated in these tables because the office of the bank at which the worksheets were left was not comparable to the offices of the other banks at which worksheets were left.

In order to interpret the 20 worksheets which remained and to judge the reliability and comparability of the data recorded it is necessary to take into account first, the relevant internal organization and operation of the 20 banks and, second, the routine in each for the stopping of payment of checks.

In regard to the relevant internal organization and operation of 19 of the 20 banks during the period of the study it appears that, in each, one office is referred to as the "main" office and the others as "branch" offices. It. also appears that in these 19 banks, the individual ledger records of the accounts of all customers, no matter at which office the customer regularly transacts his business, are kept at one office only and, with the exception of two banks, at the office referred to as the main office. A complete set of signature cards of all customers, no matter at which office the customer regularly transacts his business, is kept at the main office of each of these banks. ${ }^{24}$ In some cases branch offices have a complete set of signature cards but usually the branch office has only the signature cards of those customers who regularly transact business at that office. With the exception of 4 banks, the checks of customers of all offices are drawn on the bank generally and do not designate

23. See page 1212, infra.

24. In one bank some of whose branch offices have recently been acquired by merger the set of signature cards is not yet wholly complete. 
any office at which the check is to be paid; that is to say, the only address given is that of the city or town in which the bank is located. In the case of the other 4 banks both the name of the bank and the name and/or address of a particular office of the bank appear on the face of the check. ${ }^{25}$ In 18 banks checks are sent to, received from and returned to the clearing house (or to the banks through which they clear) by the main office at which the checks are examined for balance, signature, et cetera. In these banks checks presented through the mail are also examined for balance, signature, et cetera at the main office. In the one bank at which this is not true the clearings are handled by the branch office which keeps the individual ledger records for that bank. But in every case the only office taking care of the intra-community and inter-community clearing of checks is the office at which individual ledger records are kept. As to checks presented over the counter, however, it appears that a check, whether drawn on the bank generally or addressed to a particular office, is "paid" or certified ${ }^{20}$ at any office after such identification and after such verification of signature and determination of sufficiency of balance (by communication with the persons in charge of signature cards and individual ledger records) as the humor or judgment of the teller to whom the check is presented may dictate. Thus, the practice with respect to payment or certification of checks presented over the counter is the same, with the possible exception of the manner of verifying the signature, at all other offices of the bank as it is at the office at which individual ledger records are kept. In each of the 19 banks an order to stop payment of a check is received at any office whether or not it is the office at which the drawer regularly transacts his business. At whatever office the order is received, it is always transmitted to the person who keeps for the bank a record of all orders to stop payment received at all its offices and who attends to the relaying of the order to those offices. In every case this person is at the office at which individual ledger records are kept; in 18 cases the main office, in one a branch office. Thus, it appears that in each of the 19 banks there is an office called the main office and that in all except one bank that office is (1) the only office at which individual ledger records are kept, (2) an office at which signature cards are kept, (3) the only office at which checks presented through the clearing house or the mail are examined for

25. In one of the four the checks drawn by customers of the main office are addressed to the bank generally. Another has begun to adopt the practice of the majority but this change in practice began subsequent to the time when the 5 day study was made.

26. In one bank checks are not certified except at the main office. 
signature, balance, et cetera, and (4) the only office at which is centralized the responsibility for the recording of and, with 2 exceptions, the relaying of stop payment orders. ${ }^{27}$ In the 19 banks all offices other than the one referred to as the main office are referred to as branch offices. In the case of the one bank noted above, the centralization of individual records, signature cards, check clearing operations and responsibility for stop payment orders is in an office called a branch. This office, ${ }^{28}$ in these respects, is like the main office at the 18 other banks; the main office at this bank, like the branch offices at the others.

In the other one of the 20 banks, which operates 4 offices, the relevant internal organization and operation was like that of the 19 except that one office was, for relevant purposes, operated as if it were an entirely independent unit. The centralization of individual ledger records, signature cards, check clearing operntions and responsibility for stop payment orders for the other three offices is in an office of the bank which is called a branch. ${ }^{20}$

It appears in the record of the Steiner case that the order to stop payment was relayed from the office at which the order was received (called a branch office) to the office at which the individual ledger records were kept (called the main office), that the check was addressed to the bank generally, and that it was certified at the office at which the individual ledger records were kept. It is therefore judged that in the record, read in the light of the relevant culture of Pennsylvania, the office called the main office of the defendant, the Germantown Trust Company, referred to an office of the same type and performing the same functions as the office at which were left the worksheets in each of the 20 banks whose transactions are tabulated in Tables II, III and IV. It may be said that this conclusion was placed beyond doubt by independent investigation.

In respect of the routine followed in the 20 banks upon receipt of a stop payment order from a customer at the main office, it appear's that in 18 there is a particular person by whom or by whose assistants all stop payment orders are received or to whom they are directly referred if received by others. ${ }^{30}$ This is true whether the order is received by telephone, by letter, by telegram or from the customer in person who fills in a printed form provided by the bank. In ono of the other 2 banks, telephone orders are received by or directly

27. In each of the 18 banks the worksheets were left at this office.

28. The worksheets were left at this office. The symbol, "main office", was taken by the person who filled them in to refer to this offico and used by him in the answers to refer to this office.

29. Ibid.

30. In these 18 banks this person filled in the worksheet. 
referred to one person and all other orders to another. Telephone orders are, however, immediately communicated to the person ${ }^{31}$ to whom all other orders are directly referred so that for all practical purposes the routine in this bank is like that in the others. In the second of these 2 banks, both telephone and form orders are received by or are directly referred to a person other than the one to whom they are ultimately referred; the former directly communicates the order to the latter ${ }^{32}$ after and not before the routine for an order to stop payment has been carried out.

After the receipt of the order by the person ${ }^{33}$ by whom orders are received or to whom they are directly referred, the routine which is thereafter pursued may be divided into four processes. One of these is the examination of the individual ledger record of the customer to determine whether or not the check has been paid. In some banks the examination of the ledger record is made by the person to whom orders are directly referred. If the check has not been paid, a flash or jacket is placed upon the customer's ledger card and/or a memorandum is made and filed by the bookkeeper. Another process is the communication of the order to the paying tellers in the cages. In 10 banks the person to whom orders are directly referred notifies all the tellers; in 10 he notifies one or more tellers who notify the others. ${ }^{34}$ The mode of communication is, in some, by word of mouth; in others, by messenger; in others, by telephone; and in others, by telautograph. A record of the order to stop payment is kept in one or all of the cages. A third process is the notification of branch offices. The person to whom the notice has been directly referred attends to the notification in all except 2 banks, in one of which that task is performed by the switchboard operator and in the other by another person. The communication is made by public or private telephone or by telautograph and is received by a teller at the branch. This third process is part of the routine of all of the banks except 3 . In one of these, only one of several branch offices-a large downtown office-is notified. In the others, no branch office is notified unless the customer who notified the main office regularly transacts his

31. In this bank this person filled in the worksheet.

32. Ibid.

33. Person here means person or his assistants. "Person to whom orders are directly referred" is used hereafter to mean "person or assistants of the person by whom orders are received or to whom they are directly referred."

34. In a few banks it is said that if the stopped check is very unlikely to be presented at the counter, as for example, if it is payable to a large corporation, the order is not communicated to the paying tellers.

It should be noted that, since the vast majority of checks are presented through the clearing house and through the mail, the notification of the paying tellers is not regarded by some bankers as an especially important step. 
business at a branch office. In that event, the branch office at which he transacts his business is notified but no other. The communication to the branch office is received by a teller who notifies the other tellers present. A fourth process is the making of a permanent record for the bank of the order to stop payment. This record consists either of a file of printed forms on which have been entered the details of the order or a register in which the entries are transcribed from the forms. This record is kept by the person to whom the order is directly referred in all of the 20 banks but one, in which it is kept by the person to whom orders are ultimately referred. The order of these four processes varies from bank to bank and within each bank. There is, therefore, no routine order for the several steps taken in communicating the order to stop payment through the offices of the bank, though the first process described often precedes the others.

Orders to stop payment are given by customers to branches as well as to the main office. In the case of most of the branches of the 20 banks, there is at the branch no particular person by whom the order is received or to whom the order is directly referred. In those offices the order, whether communicated by telephone, by letter or by the customer in person, is received by any one of the tellers or other employees present. The order is relayed by public or private telephone or by telautograph, usually by the person at the branch who received it though occasionally by another employee, to the same person at the main office to whom orders, originally received at the main office, are directly referred. In the case of $\mathfrak{a}$ few branches, there is at the branch a particular person by whom the order is received or to whom it is directly referred. He is the person by whom the order is relayed to the main office.

Once the order to stop payment received at a branch has been relayed to the main office the routine thereafter, in all but 4 banks, is precisely the same as the routine of an order to stop payment which is originally received at the main office, except, of course, that the branch at which the order is received is not notified by the main office. In the 4 banks the routine differs in that the person at the branch office who relays the order to the main office also attends to the notification of each branch. However, the process of examining the ledger cards which are at the main office, the process of notifying the paying tellers in the cages at the main office, and the process of making a record for the bank which is kept at the main office are the same.

With the relevant internal organization and operation of the 20 banks and their routine for orders to stop payment described, the meaning of the answers to all the questions upon the worksheets, 
except the answers as to time, is unambiguous. "Main office" refers to the office at which the individual ledger records, signature cards, check clearing operations and responsibility for stop payment orders are centralized; "branch office" to any other office of the bank. "First notice" refers to the communication from the customer to the bank as distinguished from a "relayed" notice which refers to an intra-bank communication of the order after its receipt from the customer. Thus, except with respect to the answers as to time, the comparability of which will be discussed separately, the answers upon the worksheets are comparable.

The answers to question 1a, in 18 of the 20 banks, purport to state the time at which the order was received by the person to whom orders are directly referred. The answers do not state the time at which the order reached the bank, if it were received by someone other than the person to whom orders are directly referred. For example, in the case of a letter, the answers do not state the time at which it was opened in the mail department but state the time at which the order was received by the person to whom orders are directly referred. At the time recorded in the answers no one of the processes of routine had taken place except in one bank in which sometimes the examination of the individual ledger records had already been completed. The answers to question 1a, in the other 2 of the 20 banks, purport to state the time at which the person to whom orders are directly referred had completed his examination of the individual ledgers. Thus, it will be observed that in all of the 20 banks the times recorded in answer to question 1a may not state the time at which the order reached the bank, and in 3 banks they do not or may not state the time at which the processes of routine began, but state a time after some of the routine had been completed. In these transactions, therefore, the time interval recorded upon the worksheets for the completion of the routine will appear to be shorter than the time actually taken. Thus, the answers to question 1a are not strictly comparable but it is believed that for the purpose of this study they may be treated as if they were. The importance of the resulting error and the consequence of this procedure will be discussed below. ${ }^{35}$

The answers to question $1 \mathrm{~b}$, in 18 banks, purport to state the time at which a teller or other employee at a branch office received the order from the customer and are comparable with each other; in 2 other banks, however, the answers record the time at which the relay of the order from the branch was received by the person at the main office to whom orders are directly referred. The answers

35. See note 48 , infra, and the text to which it is appended. 
to question $1 b$ of these 2 banks are, of course, not comparable to those of the 18. The consequences of this lack of comparability will be discussed below. ${ }^{36}$

The answers to question 2 , in all but 2 banks, purport to state the time at which the relay of the order from the branch was received by the person at the main office to whom orders are directly referred. In the 2 banks, the answers to question 2 purport to state the time at which the examination of the individual ledger records had been completed and not the time at which the relay.was received by him. But these are the 2 banks at which the answers to question $1 b$ record the time of the receipt at the main office of the relayed order. Consequently, if the answers of these 2 banks to question 2 be dis-

regarded and their answers to question $1 \mathrm{~b}$ be read as answers to question 2 , the worksheets of all the banks disclose the time at which the relay of the order was received by the person at the main office to whom orders are directly referred. With this substitution made, the answers to question 2 are comparable.

The answers to question 3 , in 20 banks, purport to state the time when the person at the main office to whom orders are directly referred either knew, or, on the basis of the report of the person or persons performing each or all of the processes of routine, believed that the examination of the individual ledgers had been made, at least one of the paying tellers in the cages at the main office notified or the order given to a member of their department for them, and the relaying of the order to branches completed. ${ }^{37}$ The answers do not state the time when all paying tellers in the cages at the main office and at each branch office had been notified and the permanent record of the order made and filed or entered in the stop payment register. In some banks it is clear that one or all of the steps referred to in the preceding sentence may have been or very likely had been completed prior to the time recorded in answer to question 3, but in other banks it is equally clear that no one of them had been completed at that time. It will be observed that the interval of time actually taken to complete the routine of a stop payment order was never shorter and may have been longer than the interval of time appearing on the worksheets, the end of which was recorded in answer to question 3. The answers of the 20 banks to question 3 are judged to be comparable for the purpose of this study. Insofar as they are not strictly comparable the consequences

36. See page 1219, infra.

37. In the case of 5 transactions at one bank the person to whom ordors are directly referred neither knew nor had any basis for a belief as to whethor the relaying of the order to branches had been completed at the timo stated in answer to question 3. 
of the error which results from grouping the answers will be discussed hereafter.

It will be remembered that the routine of 3 banks differs from that of the other 17 in that all of the branches of the 3 banks are not notified. One of these 3 banks notifies a large downtown branch but does not notify its other branches; in the other 2, none of the branch offices is notified unless the customer transacts his business at a branch in which event that branch only is notified. The answers to question 3, at these banks, purport to state the time when the person at the main office to whom orders are directly referred either knew, or, on the basis of the report of the persons performing each or all of the processes of routine, believed the examination of the individual ledger record had been made and at least one paying teller in the cages at the main office and sometimes one person at one branch office only had been notified. Regarding the answers of the 3 banks simply as records of the time when like processes are completed, they are comparable to the answers of the other 17 as well as with each other. Nevertheless, since the actual transactions the happening of which is disclosed by the worksheets of these 3 banks are of types different from the actual transactions disclosed by the worksheets of the 17, the transactions of these 3 banks are not grouped with those of the 17 .

Two hundred and eighty-five stop payment transactions were recorded on the worksheets of the 20 banks. Of these, 9 were transactions in which the customer stopped the payment of a note or bill of ezchange payable at the bank and consequently were excluded as transactions not within the group under investigation. 4 other transactions, scattered over the worksheets of 3 banks were excluded because of ambiguity, patent inaccuracies or incompleteness. Though attempts were made to remore the ambiguity or to obtain the data in respect of which the records of the particular transactions were incomplete, it was not possible to obtain information sufficiently satisfactory to warrant the retention of these transactions in the study.

The comparability of the answers on the worksheets and consequently of the records of these 272 transactions has already been discussed. However, the question of the comparability of the transactions recorded on the worksheets of the Philadelphia banks during the five days of August 15 to 19 , inclusive, and of the transactions recorded on the worksheets of the banks outside of Philadelphia during the five days, September 26 to 30, remains. It is believed that the types of transactions and the frequency of each type disclosed by the worksheets would not have been substantially different had the transactions for the same five days been obtained in all 
banks. The worksheets of the two groups of banks disclose substantial similarity as to the types of transactions and their frequency of occurrence. ${ }^{38}$ The worksheets for the second five day period in the Philadelphia banks, when compared with the worksheets for the first five day period of the same banks, disclose substantial identity in the types of transactions and only slight variations in the frequency of the happening of each. ${ }^{39}$ Moreover, the number of transactions in the banks outside of Philadelphia represents such a small part of the total number of transactions that only slight inaccuracies, at most, would result in the conclusions reached were it to appear (as is believed not to be the case) that the types of the transactions

38. See Tables II, III and IV.

39.

Comparison of Workshemts of First and Second Five Day Periods in Six

Philadelphla Banks: Time (in Minutes) as RecoRded UPON WORKsHeets

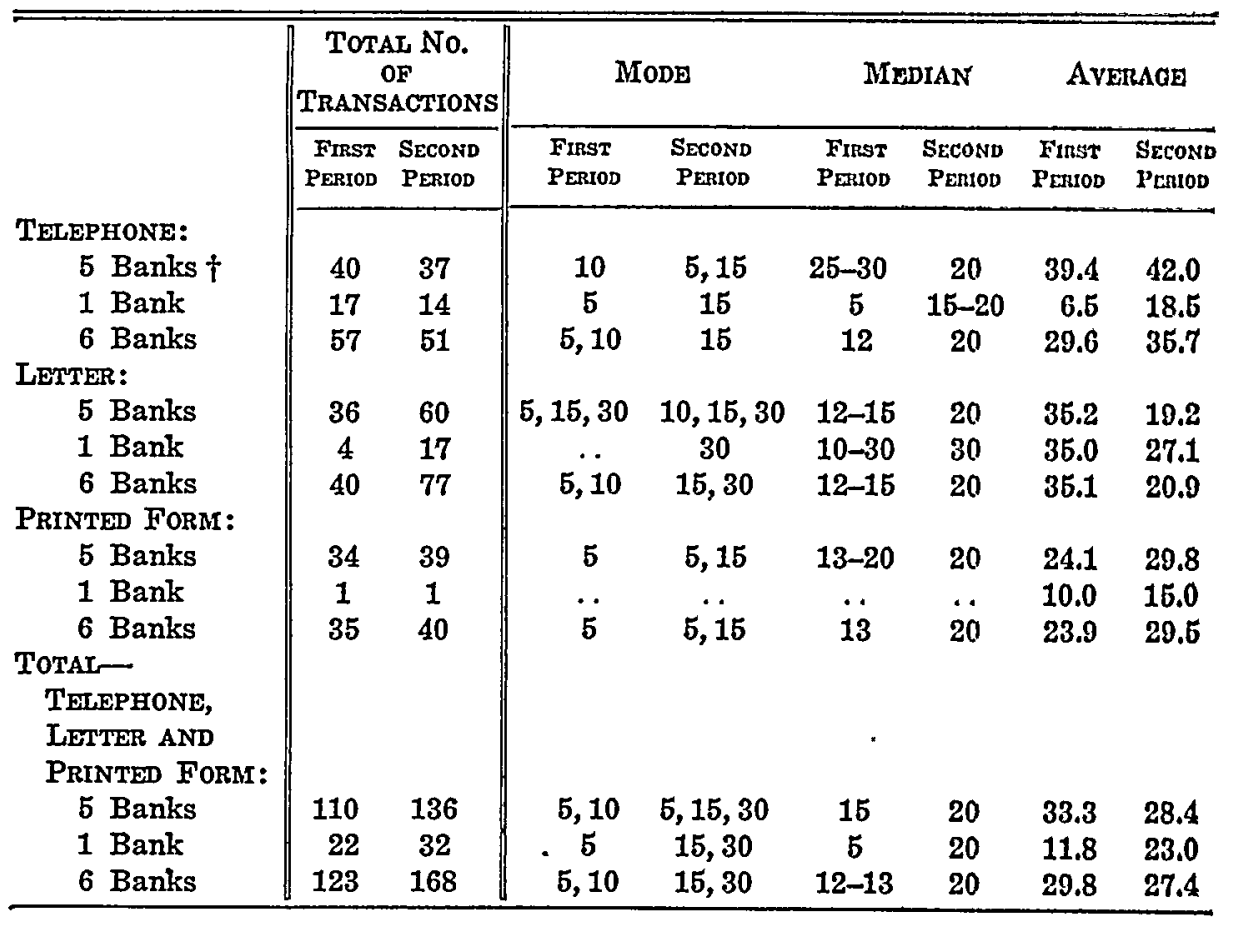

* Though the transactions of a second five day period were recorded in geven banlis, in ona of the seven the worksheets were left at an office which was not comparable to the oflece of tho other banks at which the worksheets were left (See page 1210, supra). Conscquently the transactions of that bank are not included in the above table.

t The transactions of one of the banks are tabulated separately. The difference in the timea recorded upon the worksheets between the first period and the second is attributed to the fret that during the second period the distribution of dividend payments at this bunk slowed up the performance of its regular banking activities. 
and the frequency of the occurrence of each in these banks varied greatly between August 15 to 19, inclusive, and September 26 to 30, inclusive.

In each bank, the person with whom the worksheets were left and by whom they were filled in was the person who has been referred to above as the one by whom orders to stop payment are received or to whom they are directly referred, $\$ 0$ and whose duty it is to make a record for the bank of each order. The worksheets are substantially contemporaneous records by this person of the transactions recorded. The answers record events which he knew or had reason to believe happened. The events were matters of routine. None of the answers required the disclosure of banking policy. Except with respect to the time stated in the answers to questions $1 a, 1 b, 2$ and 3 , the reliability of which will be discussed separately, it is believed that the worksheets are reliable records of the 272 transactions. The times stated in the answers to question $1 b$ as the time at which an order was originally received at a branch office are believed not to be sufficiently reliable to base any conclusions upon them. In a few cases, the times recorded are based upon times recorded at the branch office as a matter of routine; in others, they are times reported, but not contemporaneously, by the person receiving the order at the branch office as the time at which the order was received; in 2, they are estimates of the time at which the order was received at the branch, made by the person filling in the worksheet and based upon his experience of the interval of time ordinarily taken; and in 2 , the times recorded in answer to question $1 \mathrm{~b}$ do not even purport to state the time of original receipt at the branch. Consequently, the interval of time between the original receipt of an order at a branch office and the relaying of that order to the main office has not been tabulated and therefore the fact that the answers to question $1 \mathrm{~b}$ are also not comparable is of no consequence.

The answers to questions 1a, $2 * 1$ and 3 which state times of the happening of events within the main office are of an entirely different order of reliability from that of the answers to question 1b. They state times at which the person filling in the worksheet had completed a particular process of the routine or times contemporaneously reported by another employee as the time at which he had finished a particular process. Furthermore the times recorded were times, the contemporaneous noting of which either was required by the

40. See notes 30,31 and 32, supra.

41. It will be recalled that the answers to question 16 in 2 worksheets purport to state the time at which the relay of the order was received at the main office and have been substituted for the answers to question 2 in those worksheets. 
routine of the particular bank and/or was made during the drys of the study in compliance with the request of the authors. Certainly the answers to questions 1a, 2 and 3 cannot be taken to be records of precise observations of the time when particular events happened. They are, however, taken to be substantially contemporaneous and reasonably accurate records of reasonable judgments by competent persons in a familiar situation, of the times which they purport to record. There appears to be no satisfactory basis for attributing to the answers any particular margin of error. Fortunately, however, this is not necessary to accomplish the purpose of the study. In the Steiner case, the time when the order to stop payment was received from the customer at the Logan branch was judged by the manager who received it to be about $1: 45$; the time when the order was received by the teller at the main office was judged to be about the same time; and the time when the last teller in the main office was notified was judged to be 1:50. It will be observed that the persons filling in the worksheets are employees of the same class as the bank employees who testified in the Stciner case and that there would be the same tendency on the part of both the persons filling in the worksheets and the witnesses to underestimate the interval of time for completing the routine of the order to stop payment. It would seem that whatever margin of error wero attributed to the times in the answers on the worksheets, approximately the same margin of error should be attached to the times in the record of the Steiner case. Thus, for the purpose of making: a comparison of the stop payment transaction in the Steiner case with its comparable sequence, whether or not a margin of error be attributed to the times in the answers on the worksheets is of no importance. Consequently, the intervals measured by the times stated in the answers to questions 1a, 2 and 3, precisely as they are recorded, will be tabulated.

It will be recalled that the study was made in 37 of the 42 banks in Pennsylvania having more than one office and that of these, 28 were, in respect of their branch organization, comparable to the bank in the Steiner case. 272 transactions, all but 13 of the transactions of 20 of the 28 comparable banks, have been tabulated. The worksheets, so far as they go, and the interviews at the 2 comparablo banks the transactions of which were not tabulated, indicate that the types of transactions in these 2 banks were like those in the others. It is believed that the transactions of the 6 comparable banks visited which had no stop payment transactions during the period of the study and the transactions of such of the 5 banks ${ }^{41 a}$ not

41a. The relevant internal organization and operation of one of the 5 banks is, on the basis of investigation, known to be comparable to that of the 28 . 
participating in the study as were comparable in respect of their relevant internal organization and operation, do not differ in type and relative frequency of each type from the transactions of the 20 banks whose transactions were tabulated. It is believed, therefore, that the transactions tabulated are representative of the transactions of all comparable banks. The tabulated transactions are none the less representative because the study was made in the banks in Philadelphia in August and in the banks outside of Philadelphia in September. The control study made in Philadelphia for a second five day period in October and the information obtained in the course of the numerous interviews also tend to establish that the types of transactions and their frequencies do not vary with the season of the year. Unless there had been changes in the stop payment practice of the comparable Pennsylvania banks during the year and a half which separated the decision in the trial court, and the seven or eight months which separated the decision in the appellate court, from the period of the study, the transactions tabulated may be taken as representing the types of transactions and their frequencies established in the culture of Pennsylvania at the time of the decisions. There is, however, no reason to suppose that the types of transactions and their frequencies changed appreciably between the spring of 1931 and the early autumn of 1932. Certainly contacts with the banks maintained by correspondence and visit from July 1932 until May 1933 indicate that during this period there was no change in stop payment practice.

There can be no question that the class of transactions which include orders to stop payment is sufficiently large so that any type of such transactions which occurs with sufficient frequency may be a sequence, an established pattern. It is believed that the 272 transactions are a sufficiently large number to disclose the several types of stop payment transactions and to yield significant frequencies.

\section{II}

Table I, which is not devised to disclose the types of transactions and their frequencies, is presented as a convenient means of indicating some of the aspects of orders to stop payment. For this reason the data from the worksheets of the 2 banks, the transactions of which are not tabulated in the tables upon which the conclusions of the study are based, are included, as are also 4 of the transactions from the other worksheets which were not tabulated.

What the relevant internal organization and operation of the other 4 is, in unknown. 


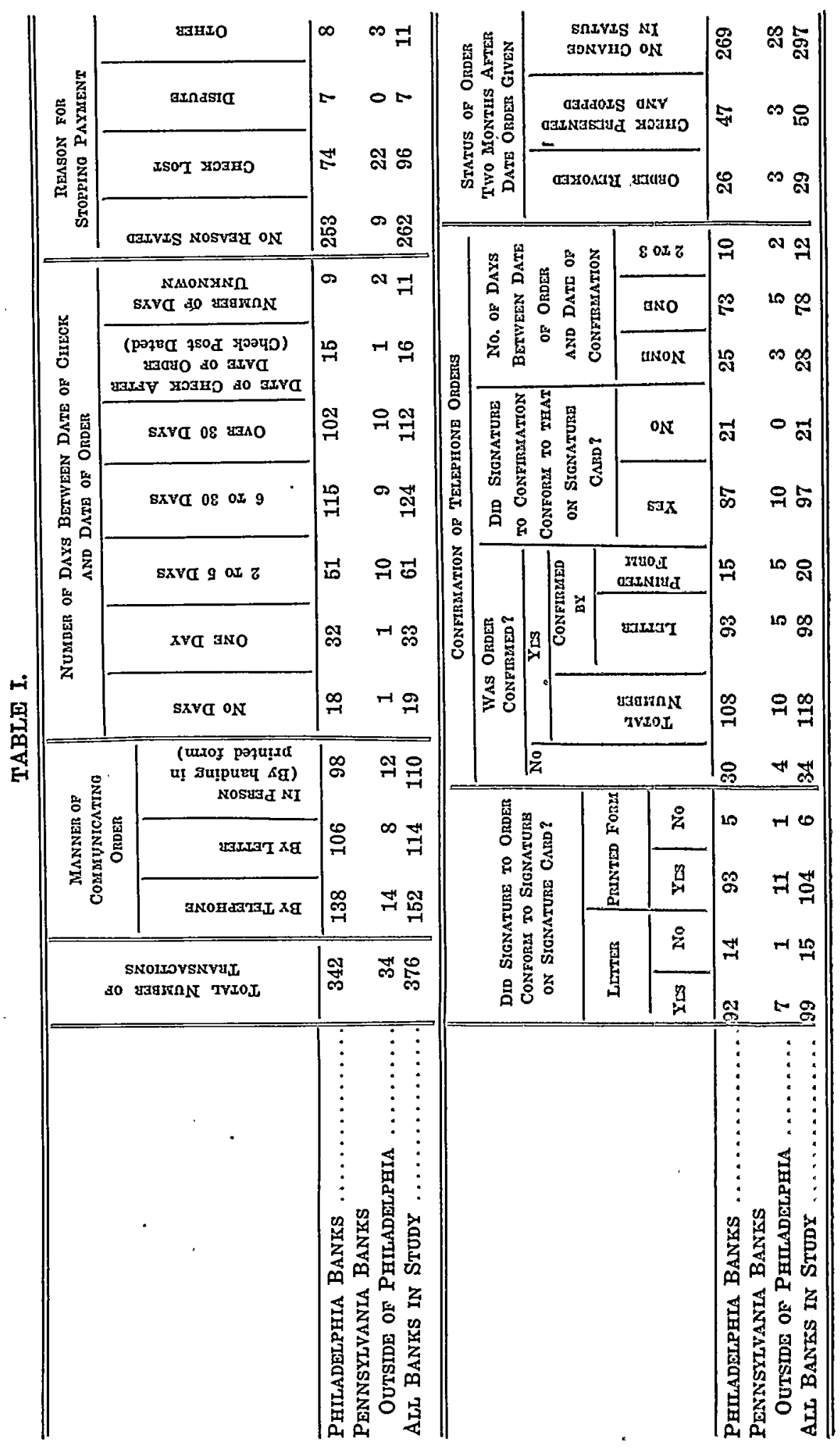


Each of the 272 transactions included in the study is reported in Tables II or III. The transactions in which the order was originally received at a branch office appear in Table II; those in which the order was originally received at the main office in Table III. These tables do not disclose any aspects of the several transactions except the mode in which the customer communicated the order, the office to which the order was communicated and the time interval between the receipt at the main office of the order (answers to question 1a) or of the relay (answers to question 2) and the completion of the processes, the happening of which is indicated by the answers to question 3. Transactions in which as a matter of routine all branches were notified are differentiated from those in which as a matter of routine all branches were not notified. Each transaction in Tables II and III is a transaction which in fact, except as to the notification of branches, conforms to the routine previously described and is like every other transaction in all aspects other than those disclosed by the tables.

Since the modal, median and average time intervals in Table II, in which orders originating at a branch office are tabulated, do not significantly differ from the modal, median and average time intervals in Table III, in which orders originating at the main office are tabulated, and since the routine of an order to stop payment after its receipt at the main office is the same, wherever the order may have originated, it appears desirable to determine the modal, median and average time intervals for the completion of the processes of routine within the main office by grouping all the transactions without regard to the office at which the orders originated. These time intervals, so determined, appear in Table IV.

TABLE IV.

\begin{tabular}{|c|c|c|c|c|}
\hline & $\begin{array}{c}\text { TOTAL } \\
\text { NUMIBER OF } \\
\text { TRANSACTIONS }\end{array}$ & MIODE & MIEDLAN & AVERAGE \\
\hline TELEPHONE: & & & & \\
\hline All of the branches notified & 92 & 5,10 & 10 & 22.60 \\
\hline Not all of the branches notified & 16 & 5 & 5 & 15.63 \\
\hline LETTER: & & & & \\
\hline All of the branches notified & 58 & 5,10 & 10 & 28.33 \\
\hline Not all of the branches notified & 16 & 5 & 5 & 11.25 \\
\hline Printed ForM: & & & & \\
\hline All of the branches notified & 78 & 5,10 & 10 & 17.22 \\
\hline Not all of the branches notified & 12 & 5 & $\mathbf{5}$ & 12.08 \\
\hline $\begin{array}{l}\text { TOTAI_TELEPHONE, LETTER AND } \\
\text { PRINTED - FORMI: }\end{array}$ & & & & \\
\hline All of the branches notified & 228 & 5,10 & 10 & 22.21 \\
\hline Not all of the branches notified & 44 & 5 & 5 & 13.07 \\
\hline
\end{tabular}


Tables II, III and IV show that there are regular types or patterns for the stopping of payment in which the order is communicated to a branch office, as well as regular types or patterns in which the order is communicated to the main office, and that there are regular types or patterns for telephoning, for mailing and for delivering in person an order to stop payment. Table IV also shows modal time intervals for the routine within the main office of orders to stop payment of 5 minutes and 10 minutes. Consequently, it is concluded that there are in Pennsylvania regular patterns or sequences for stopping payment by telephoning, mailing or delivering in person an order either to a branch or to the main office and that in making the comparisons with the Steiner case the modal time intervals of 5 and 10 minutes should be accepted.

Transactions tabulated in Tables II and III were grouped without regard to (1) the amount of the check which was stopped, (2) the description of the check in the order to stop payment, (3) the reason, if any, given by the customer for stopping payment, (4) the number of days between the date of the check and the date upon which the order was given, (5) the mode of confirming a telephone order, if confirmed, and (6) the presence or absence of conformity between the signature to a letter or printed form order to stop payment or to a confirmation and that on the customer's signature card. This grouping of transactions was judged to be justified because it was observed that the time intervals and the routine in the banks did not vary directly or otherwise with the variations in such of these aspects of behavior as were present in every transaction or with the presence or absence of such of these aspects as were not present in every transaction. ${ }^{42}$ The consequences of this grouping of trans-

42. No attempt will be made to present all the evidence for these conclu* sions. Exemplary of the evidence are the following.

TABLE A.

Retation Between Reason aNd Time (IN minutes) as Recorded Upon Worksheets for Completion of Processes of Routine in MatN Office

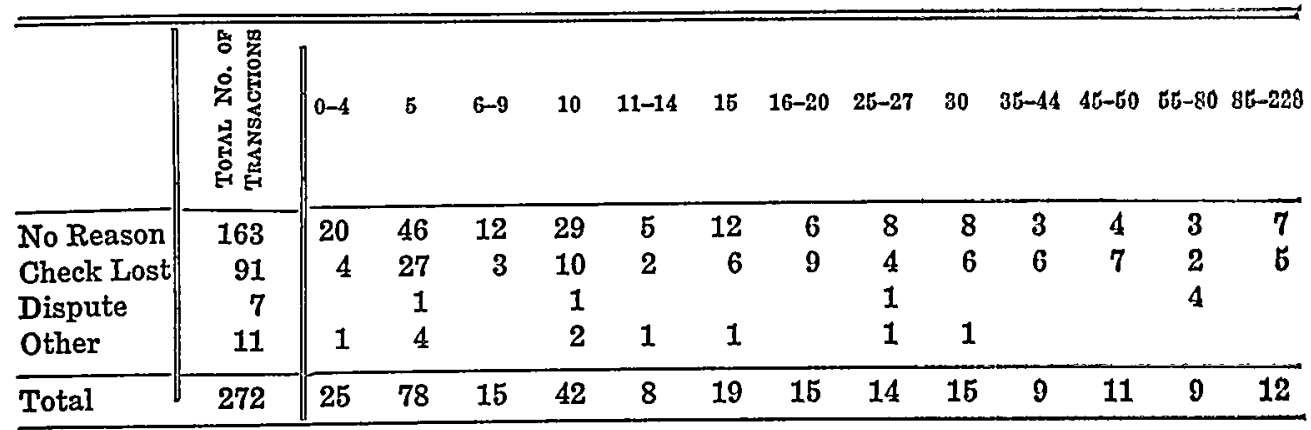


actions obviously results in Tables II, III and IV disclosing types of transactions defined in such a way as to make immaterial or irrelevant both variations in, and the presence or absence of, these aspects. Since a sequence is the function of the similarity and

\section{TABLE B.}

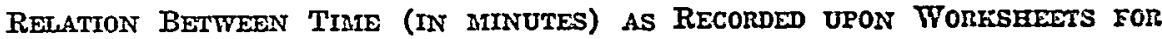
Completion of Processes of Routine in MLAIN OfFice aNd Nuliber of Days between Date of Check and Date of Order

\begin{tabular}{|c|c|c|c|c|c|c|c|c|c|c|c|c|c|c|}
\hline & 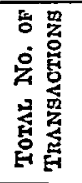 & $0-4$ & 5 & $6-9$ & 10 & $11-14$ & 10 & $16-20$ & $25-27$ & 30 & $35-24$ & $45-50$ & $85-50$ & $85-283$ \\
\hline No Days & 12 & & 3 & 1 & 2 & 2 & & 1 & 1 & & & 1 & 1 & \\
\hline One Day & 24 & 2 & 7 & & 5 & & 3 & & 1 & & 1 & & $\mathbf{2}$ & 3 \\
\hline 2 to 5 Days & 50 & 2 & 13 & 2 & 9 & 2 & 6 & 4 & 5 & 2 & 1 & 1 & 1 & $\mathbf{2}$ \\
\hline 6 to 30 Days & 96 & 8 & 26 & 5 & 18 & 2 & 3 & 6 & 5 & 5 & 4 & 7 & 2 & 5 \\
\hline Over 30 Days & 70 & 12 & 22 & 5 & 5 & 1 & 7 & 3 & 1 & 7 & 2 & 1 & 3 & 1 \\
\hline $\begin{array}{l}\text { Date of Check } \\
\text { after Date } \\
\text { of Order }\end{array}$ & 7 & & 3 & & 2 & 1 & & & & & & 1 & & \\
\hline $\begin{array}{l}\text { No. of Days } \\
\text { Unknown }\end{array}$ & 13 & 1 & 4 & 2 & 1 & & & 1 & 1 & 1 & 1 & & & 1 \\
\hline Total & 272 & 25 & 78 & 15 & 42 & 8 & 19 & 15 & 14 & 15 & 9 & 11 & 9 & 12 \\
\hline
\end{tabular}

TABLE C.

Rer.ation Betwefen Reason and itanner of Communicating Order

\begin{tabular}{l|c|cccc}
\hline & $\begin{array}{c}\text { Total No. OF } \\
\text { Transactions }\end{array}$ & $\begin{array}{c}\text { No } \\
\text { REASON }\end{array}$ & $\begin{array}{c}\text { ChECK } \\
\text { LOST }\end{array}$ & Dispute & OTHER \\
\hline Telephone & 152 & 101 & 46 & 2 & 3 \\
Letter & 114 & 83 & 28 & & 3 \\
Printed Form & 110 & 78 & 22 & 5 & 5 \\
\hline Total & 376 & 262 & 96 & 7 & 11 \\
\hline
\end{tabular}

TABLE D.

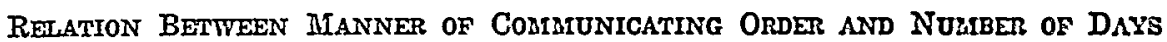
betweEn Date of CeEck and Date of Order

\begin{tabular}{|c|c|c|c|c|c|c|c|c|}
\hline & $\begin{array}{c}\text { TOTAL No. } \\
\text { OF } \\
\text { TrANSACTIONS }\end{array}$ & $\begin{array}{l}\text { No } \\
\text { DAYS }\end{array}$ & $\begin{array}{l}\text { ONE } \\
\text { DAY }\end{array}$ & $\begin{array}{l}2 \text { TO5 } \\
\text { DAYS }\end{array}$ & $\begin{array}{l}6 \text { ro } 30 \\
\text { DAYS }\end{array}$ & $\begin{array}{c}\text { OVEs } 30 \\
\text { DAYS }\end{array}$ & $\begin{array}{c}\text { DARs or } \\
\text { Cricets Afres } \\
\text { DATL or OAde }\end{array}$ & $\begin{array}{c}\text { No. OP } \\
\text { DAYa } \\
\text { Utmisiom: }\end{array}$ \\
\hline Telephone & 152 & 10 & 16 & 34 & 49 & 37 & 3 & 3 \\
\hline Letter & 114 & 1 & 4 & 16 & 42 & 46 & 1 & 4 \\
\hline $\begin{array}{r}\text { Printed } \\
\text { Form }\end{array}$ & 110 & 7 & 13 & 19 & 33 & 90 & 7 & 9 \\
\hline Total & 376 & 18 & 33 & 62 & 124 & 112 & 11 & 16 \\
\hline
\end{tabular}


frequency of transactions of a defined type, the sequences which this study discloses cannot disclose variations in, or the presence or absence of, these aspects. Therefore, in the rendering of the sequences which follows, either no mention will be made of these aspects or if any be mentioned, the variations in the aspects will be indicated in the statement of each sequence.

Furthermore, Tables II, III and IV do not give complete data as to the aspects which they do disclose. It will be remembered (1) that the answers on the worksheets which purported to state the time at which the orders were received at the branch offices were not tabulated and (2) that the interval of time, the end of which is indicated by the answers to question 3 , does not include the time taken for the distribution of the order within branch offices. Consequently, in the sequences which are stated below the time which elapsed between the original receipt of the order at a branch and its relay to the main office and also the time which elapsed between the communication of an order to the branches and its distribution within the branches, are not stated.

Tables II and III show that no one of the types of transactions in which all branches are not notified occurs with sufficient frequency to be judged to be a regular pattern or sequence. All the sequences which the tables do disclose are sequences in which all branches are notified.

It is concluded that there are twelve sequences. Only one of the two of these which are comparable to the stop payment transaction in the Steiner case is stated in full. The other is identical with the one stated except that the time interval for the routine within the main office is 10 minutes. The remaining ten differ from the two and from each other only in respect of (1) the office at which the order originates, (2) the manner in which the order is communicated and (3) the time interval for the routine within the main office.

TABLE E.

RELATION BETWEEN REASON AND NUMBER OF DAYS BETWEEN Date of Check aNd Date of ORder .

\begin{tabular}{|c|c|c|c|c|c|c|c|c|}
\hline & $\begin{array}{c}\text { TOTAL No. } \\
\text { OF } \\
\text { TrANSACTIONS }\end{array}$ & $\begin{array}{c}\text { No } \\
\text { DAYS }\end{array}$ & $\begin{array}{l}\text { ONE } \\
\text { DAY }\end{array}$ & $\begin{array}{l}2 \text { TO5 } \\
\text { DAYS }\end{array}$ & $\begin{array}{r}6 \text { To } 30 \\
\text { DAYS }\end{array}$ & $\begin{array}{c}\text { OVER } 30 \\
\text { DAYS }\end{array}$ & $\begin{array}{c}\text { DAYO OP } \\
\text { CHECK AFTER } \\
\text { DATE OF ORDER }\end{array}$ & $\begin{array}{c}\text { No, OF } \\
\text { DAYA } \\
\text { UNKNOWN }\end{array}$ \\
\hline No Reason & 262 & 14 & 25 & 44 & 80 & 82 & 8 & 8 \\
\hline Check Lost & 96 & 2 & 4 & 16 & 41 & 27 & 5 & 1 \\
\hline Dispute & 7 & & 3 & & 1 & 2 & 1 & \\
\hline Other & 11 & 2 & 2 & 2 & 2 & & 1 & 2 \\
\hline Total & 376 & 18 & 34 & 62 & 124 & 111 & 15 & 12 \\
\hline
\end{tabular}


One of the two comparable sequences is:

1. At any time after the drawing and delivery of a check and before its presentment the customer telephones to a person (either an officer, manager, paying teller or bookkeeper) at a branch office (either the office at which the customer regularly transacts his business or at another) an order to stop payment of a check which he identifies (by reference to the number, date, payee and amount, or by reference to some of them), with or without stating a reason for stopping payment. Thereafter he does (by letter or by printed form, the signature to which either does or does not conform to the signature on the customer's signature card) or does not confirm the order.

2. - minutes thereafter a person (the person who receives the order or some other person) at the branch office communicates (by telephone, by telautograph or by messenger) the order to stop payment to the person to whom orders are directly referred at the main office (a member of the paying teller's or the booklkeeping department).

3. Within five minutes thereafter, the person at the main office who receives the order notifies (by word of mouth, by messenger, by telautograph or by telephone): (1) a person in the bookkeeping department who instructs another to examine or himself examines the individual ledger record of the customer and who places a flash or jacket on the ledger record or files a memorandum; (2) at least one person in the paying teller's depar'tment (paying teller or messenger); and (3) one person (officer, manager, paying teller or bookkeeper) at each branch office.

4. - minutes after the person at each branch is notified he notifies (by word of mouth, by telephone, by telautograph or by messenger) at least one paying teller at his branch.

Tables I, II, III and IV also establish the sequences, beginning with the drawing of the check referred to in an order to stop payment, with which the several stop payment sequences are regularly associated and those with which the stop payment sequences are not; that is to say, they show with which of the sequences beginning with the drawing of the check the stop payment sequences are in institutional relation. The tables show that a check referred to in an order to stop payment either is not presented at all or is presented after the completion of the stop payment sequence and dishonored on presentment; that is, stop payment sequences are always associated with, i.e., they are in institutional relation with, sequences in which a check referred to in an order to stop payment is not presented at all or with sequences in which such a check is both presented and dishonored after the completion of the stop payment sequence. 
They also show that a check referred to in an order to stop payment is not presented and honored after the completion of the stop payment sequence; that is, there are no sequences which, after the completion of the stop payment sequences, conclude with the presentment and honoring of the check. It is clear that both a check which is presented before an order to stop payment is given and also a check which is presented to a person to whom an order to stop payment has not been communicated are honored. It is equally clear that in either of these situations the routine of an order to stop payment is never completed, ${ }^{43}$ except in the event that notification to the person by whom the check has been honored completed the routine. In other words transactions in which checks are presented and honored are rarely, if ever, accompanied by stop payment transactions (though they may be accompanied by behavior which falls short of being a stop payment transaction) ; that is, stop payment sequences are not associated with, i.e., they are not in institutional relation with, sequences in which checks are presented and paid. Thus it appears that stop payment sequences appear only in sequence-series which include either a sequence in which a check, referred to in an order to stop payment, is never presented or a sequence in which such a check is both presented and dishonored after the completion of the stop payment sequence; and it appears that stop payment sequences never appear in sequence-series which include a sequence in which a check referred to in an order to stop payment is presented and honored.

III.

The specific end of the present study is to observe first, the association between the court's refusal to intervene, by attempting to attach the opposite consequence to that which actually followed the transaction-series, and the type and degree by which the transactionseries, which concluded with the bank's refusal to honor the plaintiff's demand for $\$ 213$, deviated from a sequence-series which concludes with the honoring of the customer's demand for $\$ 213$, and second, the association between the court's refusal to intervene and the type and degree by which the transaction-series deviated from a sequence-series which concludes without a further demand for $\$ 213$. These associations are observed first, by comparing the transaction-series, transaction by transaction, viewed as a device to

43. The interviews disclosed that the individual ledger record of the customer was examined immediately upon the receipt of an order to stop payment or very shortly thereafter. If such examination disclosed that the check had been paid, no part of the routine was thereafter completed. 
the opposite consequence, i.e., demand for $\$ 213$ honored, with the comparable sequence-series having the consequence of demand for $\$ 213$ honored, viewed as a device for that consequence, and secondly, by comparing the transaction-series, viewed as a device to the consequence of no demand for $\$ 213$, with the comparable sequence-series having the consequence of no demand for $\$ 213$, viewed as a device for that consequence. ${ }^{44}$

The making of these comparisons requires that the sequences in Pennsylvania for the stopping of payment of a check be known. These sequences have been stated in detail except as to time intervals. The study does not disclose, in the case of any transaction, the time which may have elapsed between the communication of the order from the main office to the last branch notified and the completion of the communication of the order within the branch offices. $^{45}$ Nor does it disclose, in the case of orders given by the customer at a branch office, the time which elapsed between the giving of the order and its relay to the main office. ${ }^{26}$ But Tables II, III and IV show in the case of all transactions, the time interval for the completion of the routine within the main office. ${ }^{4 t}$ Consequently, in making a comparison of the transaction-series in the Steiner case with a comparable sequence-series, it will be impossible to observe directly the similarity of, or the difference between, the total time interval in the stop payment transaction of the transactionseries and the total time interval of the comparable stop payment sequence in the sequence-series. It is a necessary conclusion, however, that the sequential time interval for the completion of the whole routine is greater than the sequential time interval for the completion of part of the routine. And if it were to appear that the time interval in the transaction were less than or equal to a part of the total time interval of the comparable sequence, a comparison might be made; though a comparison could not be made if the time interval were greater than part of the time interval of the comparable sequence, since the time interval of part only is known. But from the tables it appears that for the completion of the routine within the main office, there are two modal time intervals, one of 5 minutes and one of 10 , a median time interval of 10 minutes, and an average of 22 minutes. ${ }^{48}$ In the Steiner case the record, ac-

44. Mioore and Hope, supra note 3, at 707-719; MLoore and Sussman, supro note 4.

45. See page 1226, supra.

46. Ibid.

47. See page 1223 , supra.

48. It will be recalled (see page 1115, supra) that some of the answers to question 1a were not strictly comparable with the others. Nevertheless they 
cording to the defendant's case, established by the testimony of three of its tellers, discloses that the time interval from the original receipt of the order at the branch office to the communication of the order to the last teller in the main office was 5 minutes. The general finding in the trial court was for the defendant, and the trial court's denial of the plaintiff's motion for judgment notwithstanding the finding was affirmed. Consequently, if 5 minutes is taken as the time interval in the Steiner case, it is possible to proceed with the comparison.

In the first comparison of the transaction-series it is viewed 'as a device to the consequence of demand for $\$ 213$ honored. The comparable sequence-series, having that consequence, is composed of three sequences. In the first a check for $\$ 213$, the full amount of the balance, is both presented and dishonored after the completion of the second sequence which is a stop payment sequence. The stop payment sequence which is chosen is the stop payment sequence described, ${ }^{49}$ the sequence in which an order to stop payment is telephoned by the customer to a branch office, relayed to the main office and thereafter distributed throughout the main and the branch offices, and for which the modal time in the main office is 5 minutes. The third sequence, of course, is one in which a second check for $\$ 213$, the full amount of the balance, is thereafter presented and honored.

The comparison, it will be recalled, is made transaction by transaction. The first transaction, in which the check is certified (before the lapse of the modal time for completion of the routine of an order to stop payment, and before the completion of the routine), and the comparable sequence in which a check is dishonored (after the lapse of the modal time for completion of the routine of an order to stop payment and after the routine is completed) are compared as devices having the consequence of the honoring thereafter of another check for $\$ 213$. When this comparison is made it is clear that the transaction is an unfamiliar, uncertain, inefficient and risky device for the accomplishment of the consequence; that is, the transaction deviates grossly from its comparable sequence..$^{\text {to }}$

were tabulated as if they were and the modal, median and avernge time intervals were calculated accordingly. Since the resulting error, as was pointed out, must be in the direction of shortening the modal, median and average time intervals with which the actual time interval in the Steiner case is to be compared, the error appears to make the comparison a more exacting test of the hypothesis.

49. See page 1227, supra.

50. Moore and Hope, supra note 3, at 717-719. 
The second transaction comprises the plaintiff's order to the branch office given over the telephone to stop payment of the check for $\$ 213$, the relay to a teller at the main office and the communication of the order to all the paying tellers at the main office. The last of them to be notified had certified the check before the communication to him of the order. The time which passed between the receipt of the order at the branch and its communication to the teller who had certified the check was 5 minutes. The transaction does not include the carrying out of any of the processes of routine except the relay of the order from the branch office and the notification of the tellers at the main. The comparable sequence includes, in addition to the processes of routine carried out in the transaction, the notification of the bookkeeping department, the examination of the customer's ledger record to determine whether the check was paid, the relay of the order to and its distribution within each branch office, and the making, at the main office, of a permanent record for the bank. All of the processes which comprise the sequence are completed before the presentment of the check referred to in the first transaction. The time which sequentially (modally) passes during the carrying out of part of the processes of routine which are accomplished at the main office, namely, the receipt of the relay at the main office, the notification of the bookkeeping department and the examination of the individual ledger records, the notification of the paying tellers department and the notification of each branch office, is 5 minutes. The sequential time for the completion of the entire routine beginning with the original receipt of the customer's order at the branch office is more than 5 minutes. The transaction and its comparable sequence are compared as devices to prevent the honoring of the check for $\$ 213$ referred to in the first transaction. So compared, the transaction is found to deviate grossly from the sequence.51 A transaction which is incomplete in respect of the communication of the order to stop payment to the persons who might honor a check, i.e., to boolkkeepers and paying tellers, and in which the time for notifying the persons who might honor had not elapsed when the check was certified, is a much less certain and familiar and a much more risky device to prevent the honoring of the check than a sequence in which sufficient time for notifying bookkeepers and paying tellers had elapsed before the check was presented and in which they had, in fact, been notified.

The third transaction, in which the plaintiff's demand for $\$ 213$ was refused, is to be compared with the sequence in which a check for $\$ 213$ is honored. The transaction is the consequence of the

51. Ibid. 
antecedent transactions in the transaction-series and the sequence is the consequence of the antecedent sequences in the sequence-series. They are to be compared as consequences. But it is assumed that the most significant difference between alternative consequences is the difference between them as devices to further consequences. A comparison of them as devices to further consequences discloses a gross deviation, just as a direct comparison of them as consequences shows them to be wholly different. ${ }^{62}$

Thus the comparisons disclose that the judgment in the Steiner case, that the plaintiff might not recover the amount of his demand, followed a transaction-series which included three deviational transactions. The first two transactions upon comparison deviated grossly from their comparable sequences. The third also deviated grossly. The association between the gross deviation of the device (the first two transactions) from its comparable institutional device (the first two sequences) and the degree of deviation of the consequence (the third transaction) from the consequence suggested by the institution (the third sequence) indicates that the degree by which the behavior of the parties deviated may be significantly connected with the decision.

It will be recalled that the transaction-series is also" compared with a sequence-series having the consequence of no demand for and no payment of $\$ 213$, which is the consequence most like that of the transaction-series. The sequence in that sequence-series comparable to the first transaction is one of certification of the check for $\$ 213$ (the payment of which the customer has never attempted to stop). There is no sequence comparable to the second transaction. It has been pointed out that there is no stop payment sequence which is in institutional relation with, i.e., associated with, al sequence in which a check is honored, though stop payment behavior which falls short of being a completed stop payment transaction may accompany a sequential transaction in which the check is honored. A stop payment sequence, therefore, cannot appear in a sequenceseries containing a sequence in which the check is honored. The consequence of this sequence-series which is comparable to the third transaction, the consequence of the transaction-series, is no demand for and no payment of $\$ 213$.

A comparison of the first transaction in which the check is certified (before the order to stop payment is communicated to the certifying teller) with its comparable sequence in which the check is certified (no order to stop payment having been given) discloses that the behavior of the parties stated in the transaction

52. Moore and Sussman, supra note 4, at 1219, 1232. 
is identical with that in the sequence. The fact that in the Steiner case another transaction for the stopping of payment of the check had begun before the check transaction was complete is, of itself, not sufficient to make the transaction of certifying the check any less familiar, certain, or efficient a device to effect an extinguishment of the customer's deposit currency, nor one involving a greater risk of loss than is the sequence. ${ }^{53}$

Since there is no comparable stop payment sequence in the sequence-series for the second transaction, i.e., no institutional pattern to serve as a model with which to compare the second transaction, the comparison of the second transaction and "no stop payment sequence" must be made indirectly. It is accomplished by comparing the transaction with the opposite of "no stop payment sequence," i.e., with a stop payment sequence. ${ }^{5 *}$ But that comparison has already been made and the deviation judged to be gross. 50 Thus if the second transaction deviated grossly from the opposite of that with which it is to be compared, of necessity it deviated but slightly from that with which it is to be compared. ${ }^{06}$

The third transaction, in which the plaintiff's demand for \$213 was refused, is to be compared with the consequence of the sequenceseries, no demand for and no payment of $\$ 213$. It will be recalled that consequences are compared as devices to further consequences. Such a comparison discloses that, as a device to further consequences, the transaction deviates but slightly; compared directly as consequences, the transaction and the comparable behavior are alike. ${ }^{57}$

Thus the comparisons disclose that the judgment in the Stciner case, that the plaintiff might not recover the amount of his demand, followed a transaction-series which included three transactions. The first, upon comparison, appeared identical with its comparable sequence and the second deviated but slightly. The third also deviated but slightly. The association between the slight deviation of the device (the first two transactions) from its comparable institutional device (the first sequence not followed by any sequence) and the slight deviation of the consequence (the third transaction) from the consequence suggested by the institution, indicates that the degree by which the behavior of the parties deviated may be significantly connected with the decision.

53. Note 50, supra.

54. MToore and Sussman, supra note 4, at 1219, 1234-1235.

55. See page 1231, supra.

56. Note 54, supra.

57. Note 52, supra. 
In the foregoing comparisons the sequential (modal) time which was adopted was the 5 minute mode disclosed by Tables II, III and IV. If the time interval of the only other mode, 10 minutes, were adopted, the time interval of the transaction, 5 minutes, would still be less than the sequential time for part of the sequential behavior and therefore comparisons like those already made could be undertaken. Obviously if they were, their results would be the same. If, for any or no reason, the median time interval of 10 minutes or the average time interval of 22 minutes were chosen, similar comparisons which, if made, would disclose the same results, could be undertaken.

It is interesting to note the significance which might be attributed to the results of the foregoing comparisons of the transaction-series, in which the time interval of the stop payment transaction was taken to be 5 minutes, with each of the alternative comparable sequence-series. Upon the comparison of the transaction-series with the first comparable sequence-series, the first two transactions, viewed as a device, deviated grossly from the standard device claimed by the plaintiff to be comparable and was, therefore, not accorded by the court a legal consequence conforming to the institutional consequence which would have followed had the standard device been used. The third transaction, viewed ás a consequence of the first two, likewise deviated grossly from the standard consequence of the institutional device from which the device used in the Steiner case also grossly deviated. Consequently, the institutional consequence was not chosen as the legal consequence. Upon the comparison of the transaction-series with the second comparable sequenceseries, the first two transactions, viewed as a device, deviated slightly from the standard device claimed by the defendant to be comparable, and was, therefore, accorded a legal consequence conforming to the institutional consequence which would have followed had the standard device been used. The third transaction, viewed as a consequence of the first two, also deviated slightly from the standard consequence of the institutional device from which the device used in the Steiner case slightly deviated. As a result, the institutional consequence which would have followed had the device not deviated at all was chosen as the legal consequence.

Consequently, just as did the study of the Callaham, Delano and Goldstein cases, ${ }^{\square 8}$ so does the study of the Steiner case tend to justify the conclusion that there is a significant association between three of the factors in a litigation-situation, namely, the behavior of the

58. See Moore and Sussman, supra note 4, at 1219-1250, especially 12401250. 
litigants, the institutional patterns of the jurisdiction and the decision, which may be expressed in terms of the degree by which the behavior of the litigants deviates from the comparable sequences.

It will be recalled that the record discloses that the plaintiff's own testimony, which was contradicted, was that the order was communicated by him to the branch office about $1: 30$. It is possible that despite the defendant's evidence, the trial court might have inferred a time interval of 20 minutes between the plaintiff's original communication of his order to the branch office and the notification of the teller who certified the check. It is also possible that, on the motion for judgment notwithstanding the general finding of the trial court for the defendant, the courts might have taken the general finding to include a 20 minute interval. ${ }^{59}$ If the 20 minute should be substituted for the 5 minute interval in the stop payment transaction in the Steiner case, then, since the sequential (modal) times for that part of the sequential behavior which occurs in the main office is less than the time for the transaction, an indirect comparison of the transaction can not be made.60 Whether the sequential time for the whole sequence is greater, equal to, or less than the time interval of the transaction is unknown, and no conclusions can be drawn by either direct or indirect comparison as to the degree of deviation of the transaction from its comparable sequence. It may be said, however, that the study disclosed nothing which would lead one to expect that the sequential time for the whole sequence, including the relay of the order from the branch to the main office, the relay from the main office to the branch offices and the disposition of the order within the branches, would be found upon investigation to be less than 20 minutes.

59. The report of the case in $104 \mathrm{~Pa}$. Super. Ct. 38 (1931) is misleading as to the time interval disclosed by the record to which the appellate court was reacting.

60. See page 1229 , supra. 